PEDRO PÉREZ CASTROVIEJO

Ministerio de Trabajo y Seguridad Social,

Colección Historia Social n²5, Madrid, 1992, 426 páginas

\title{
CLASE OBRERA Y NIVELES DE VIDA EN LAS PRIMERAS FASES DE LA INDUSTRIALIZACIÓN VIZCAINA
}

José Ignacio Martínez Ruiz*

El libro de Pérez Castroviejo tiene como objeto el estudio de los niveles de vida de los trabajadores de las minas y, sobre todo, de las fábricas vizcaínas en el último cuarto del siglo XIX y primera década y media del siglo XX, periodo en el que Vizcaya se convirtió en una sociedad plenamente industrial. Consta de una introducción y de cinco capítulos dedicados al proceso de formación y a las características de la población minero-fabril (I), al estudio de los salarios nominales y reales (II), a las condiciones de trabajo (III), a las relaciones laborales resultantes de la interacción entre trabajadores, patronal y Estado (IV) y a la conflictividad laboral (V). Consta también de unas conclusiones, varios apéndices y dieciséis páginas de fuentes y bibliografía.

Podriamos sintetizar las conclusiones del texto utilizando las matizadas palabras del propio Pérez Castroviejo: "existen más razones para pensar en una mejora relativa del nivel de vida de la clase trabajadora en su conjunto que de lo contrario" (pp. 368). No añadir nada más sería, sin embargo, cometer una gran injusticia con el libro reseñado $\mathrm{y}$, sobre todo, con su autor.

Ante la imposibilidad de ser exhaustivos, tan sólo nos referiremos con un mínimo detalle a dos aspectos del trabajo: las fuentes utilizadas y los temas planteados en la primera parte del capítulo III.

Por lo que se refiere a aquellas, Pérez Castroviejo ha tenido la fortuna de acceder y el acierto de utilizar como una de las fuentes básicas de su estudio, los libros de nóminas y de matrícula y las fichas personales de los trabajadores de Altos Hornos de Vizcaya, empresa que a comienzos del siglo XX con-

* José Ignacio Martínez Ruiz es Catedrático y Profesor de la Escuela Universitaria de Relaciones Laborales de Sevilla 
centraba una tercera parte del empleo provincial en el sector siderometalúrgico. La riqueza de matices del conjunto de la obra y, especialmente, de los capítulos I a IV, resulta imposible de explicar sin tener en cuenta que su autor ha reconstruído las "vidas laborales" de los casi 24.000 trabajadores que formaron parte de la plantilla de Altos Hornos de Vizcaya hasta 1915.

En cuanto al capítulo III, lo primero que debemos decir es que su título "Las condiciones de trabajo" - resulta restrictivo en relación con los temas tratados y que, tal vez, habría sido más acertado utilizar alguna expresión que hiciera referencia a la organización del trabajo, sin duda el tema más importante de cuantos se abordan en el mismo.

Este capítulo es especialmente interesante por cuanto nos sitúa ante el hecho de que las series de salarios nominales y reales significan muy poco si no conocemos también el número de días de trabajo al año, la evolución del desempleo o los sistemas internos de promoción, cuestiones todas tratadas con acierto por Pérez Castroviejo.

En otros casos, sin embargo, presumiblemente por las limitaciones impuestas por la documentación, el autor apenas puede hacer otra cosa que insinuar o sugerir ideas en torno a una serie de cuestiones muy relevantes para el estudio del trabajo en las minas y fábricas de Vizcaya en concreto y de la historia del trabajo en general. Por ejemplo, en relación con el tema de la organización de la producción y del control del trabajo, el autor destaca que la elección entre las distintas modalidades de trabajo y pago existentes en las empresas vizcaínas - "a jornal", "a prima", "a destajo", "a contrata" -, correspondió en gran medida a los propios trabajadores. ¿Hasta dónde llegaba, si es correcto utilizar la expresión, este "control" obrero de la organización del trabajo?. ¿Cómo afectó al mismo el proceso de cambio tecnológico que vivió la siderugia vizcaína desde finales del siglo XIX?. ¿Se descualificó por ello la fuerza de trabajo con anterioridad a la P.G.M.?. Otro ejemplo es el de las prácticas de paternalismo industrial utilizadas por Altos Hornos de Vizcaya y su progresiva burocratización a partir del establecimiento, el año 1903, de reglas fijas a la hora de fijar pensiones, ayudas, etc., un tema sobre el que apenas se ha escrito nada en nuestro país. 